\title{
Family planning counselling and use among clients seeking abortion services in private health facilities in Kenya
}

\author{
Francis Obare, ${ }^{1}$ Wilson Liambila and Harriet Birungi \\ Population Council, Nairobi, Kenya
}

\begin{abstract}
This paper examines family planning service provision and use among clients seeking abortion services in private health facilities in Kenya. Data are from observations of client-provider interactions and exit interviews conducted in May-June 2013 with I 25 clients from 30 private clinics in Kisumu, Nairobi, and Mombasa counties. Analysis entails simple frequencies, cross-tabulations with Chi-square tests, and estimation of multivariate logistic regression models. The results show that: (I) although $78 \%$ of the clients had used family planning before, it was mostly short-acting methods such as condoms (44\%), injectables (35\%), oral (40\%) and emergency (26\%) pills; (2) providers did not counsel clients on family planning in $20 \%$ of the consultations while clients were offered a method in $47 \%$ of the consultations; and (3) among clients who had ever used family planning and accepted a method during the visit, $60 \%$ chose a different method with the shift being from short-acting to long-term methods.
\end{abstract}

Keywords: Family planning; counselling and use; abortion services; private health facilities; Kenya

\section{Résumé}

Ce papier examine l'offre et l'utilisation des services de planification familiale chez les clients qui recherchent fréquentant les services d'avortement au niveau des établissements privés de santé privés au Kenya. Les données sont issues d'observations des interactions client-prestataires de services et des entretiens de sortie menées entre Mai - Juin 2013 auprès de 125 clientes provenant de 30 cliniques privées au niveau des zones de Kisumu, Nairobi, Mombasa. Les analyses utilisées portent sont basées sur des fréquences simples, des tableaux croisés avec des tests de Khi2 et sur des analyses multivariées utilisant de modèles de régression logistique. Les résultats indiquent que: (I) bien que $78 \%$ des clients avaient utilisé la planification familiale auparavant, il s'agissait surtout de méthodes de courte durée d'action telles que les préservatifs (44\%), les injectables (35\%), des pilules classiques orales (40\%) et des pilules pour la contraception d'urgence (26\%); (2) les prestataires ne donnaient de conseils sur la planification familiale aux clientes lors de la consultation (20\%) alors que $47 \%$ d'entre elles ont reçu une méthode de planification familiale, et (3) parmi les clients ayant déjà utilisé la planification familiale et accepté une méthode lors de la visite, $60 \%$ avaient choisi une méthode différente avec un passage des méthodes à courte durée d'action vers les méthodes à longue durée d'action.

Mots clés: La planification familiale; Conseils et de l'utilisation; Les services d'avortement; Établissements de santé privés; Kenya

\footnotetext{
${ }^{1}$ Address for correspondence: Francis Obare, Population Council, Ralph Bunche Road, P.O. Box 17643, Nairobi 00500, Kenya: Tel: +254-20-2713480-3; Fax: +254-20-2713479; E-mail: fonyango@popcouncil.org.
} 


\section{Introduction}

The World Health Organization (WHO) estimates that globally, approximately 210 million pregnancies occur each year with over 135 million resulting liveborn infants while the remaining 75 million end in stillbirth or (spontaneous or induced) abortion (WHO 20II). About 80 million pregnancies are unintended and about 42 million of these pregnancies (or I in 5) end in induced abortions each year, 36 million of which take place in low and middleincome countries (Benson 2005; Sedgh et al. 2007; Singh et al. 2009; WHO 2004). Twenty-two million of these abortions are considered unsafe or performed by untrained practitioners and provided in unhygienic settings (WHO 2004). Unsafe abortion accounts for $13 \%(47,000)$ of global maternal deaths while about 60 per cent of abortion-related deaths take place in Africa (Shah and Åhman 2008; United Nations 20I0). In Kenya, 35\% of maternal deaths are attributable to unsafe abortion (Centre for Reproductive Rights 2010; Ministry of Health 2003). Over 2,600 women die annually from complications of unsafe abortion and over a third of the women admitted with abortion complications were in the second trimester of pregnancy when risks of severe complications and mortality are substantially higher in the country (Centre for Reproductive Rights 2010).

Public debate on abortion and on proposals to liberalize the abortion law has been on-going for several years in Kenya (Brookman-Amissah and Moyo 2004). With the passing of a new Constitution in 2010, there has been renewed interest at all levels in the areas of the right to health and the need to reduce the high levels of maternal morbidity and mortality arising from unsafe abortion in the country (Republic of Kenya 20I0; 2012). Moreover, medical abortion using Misoprostol and Mifepristone has been classified by $\mathrm{WHO}$ as a safe and effective method to stop an unwanted pregnancy up to 9 completed weeks since the last menstrual periodfirst trimester (WHO 20I2). Misoprostol is registered in Kenya as a multi-purpose drug whose indications include duodenal ulcer, gastric ulcer, treatment of incomplete abortion and miscarriage, treatment and prevention of post-partum haemorrhage (PPH), treatment of missed abortion in first trimester, treatment of intrauterine fatal death and cervical ripening. Mifepristone is also registered as a medication indicated for duodenal ulcer, gastric ulcer, cervical ripening and as a uterotonic drug. The availability of these two drugs is expected to replace surgical and non-surgical invasive methods that have previously been used to terminate pregnancies, both illegally and legally (Ong'ech et al. 2008).

In spite of the developments, access to information and services on medical abortion in Kenya is mainly through private practitioners while public health facilities mostly provide post-abortion care services (Wamugi et al. 2014). Moreover, the use of modern family planning methods plays a critical role in reducing the incidence and prevalence of induced abortion by preventing unwanted pregnancies (WHO 2012). However, most women in Kenya obtain family planning methods from public health facilities (Hutchinson et al. 20II; Kenya National Bureau of Statistics [KNBS] and ICF Macro 20I0). There is therefore limited understanding of the provision of family planning information and services to clients seeking abortion services in private health facilities in the country. This paper uses data from observations of client-provider interactions during consultations and exit interviews to examine family planning service provision and use among clients seeking abortion services in private health facilities in Kenya. It specifically focuses on prior use of family planning by the clients, whether providers counselled clients on family planning and offered clients a method during consultation as well as whether clients accepted a method. It further explores whether there were significant differences in the provision of these services by provider and client background characteristics.

Available evidence indicates that the private sector plays a major role in health service provision in developing countries especially those services that are not subject to market failures such as curative care and family planning (Berman and Rose 1996; Brugha and Zwi 1998; Bustreo et al. 2003). Howev$\mathrm{er}$, there are concerns about the quality of services provided given the diverse nature of the private sector in these settings (Berman and Rose 1996; Brugha and Zwi 1998; Mills et al. 2002). A systematic review of the literature further showed that services provided by the private sector might not be accessible to the poor (Patouillard et al. 2007). In the context of abortion, perceived high costs of services in private health facilities might lead economically disadvantaged women to resort to unsafe abortions with the attendant morbidity and mortality risks (Wamugi et al. 20I4). However, even for those who might afford the services of private providers, the type of care they receive might be affected by various factors including the available resources, availability of appropriate services, client choice, technical competence of providers, and interperson- 
al relations with clients (Bruce 1990; Gresh and Maharaj 2014). In particular, the provision of family planning services to abortion clients in private health facilities might be affected by the availability of the methods or the technical competence of the providers to offer the methods.

\section{Context}

Estimates from the 2008-2009 Kenya Demographic and Health Survey (KDHS) show that the contraceptive prevalence rate (CPR)-the proportion of currently married women aged 15-49 years using any family planning method-was $46 \%$ (KNBS and ICF Macro 2010). There were, however, wide variations in CPR by women's socio-demographic characteristics. CPR was, for instance, higher in the urban compared to rural areas $(53 \%$ and $43 \%$ respectively; KNBS and ICF Macro 2010). It was also highest in Central (67\%) and lowest in North Eastern region (4\%; KNBS and ICF Macro 20I0). Nairobi, Eastern, Western, Rift Valley, Nyanza and Coast regions had, on the other hand, CPR of $55 \%, 52 \%, 47 \%, 42 \%$, $37 \%$ and $34 \%$ respectively (KNBS and ICF Macro 2010). CPR was also more than four times higher among women with secondary and above level of education compared to those with no education (60\% and I4\% respectively; KNBS and ICF Macro 2010). CPR was largely driven by use of modern methods (39\% of currently married women; KNBS and ICF Macro 2010). Use of family planning was, however, higher among sexually active unmarried women compared to those who were married. In particular, $50 \%$ of sexually active unmarried women aged 15-49 years were using any family planning method while $45 \%$ were using a modern method (KNBS and ICF Macro 2010).

Among currently married women, the most commonly used modern methods of family planning include injectables $(22 \%)$, oral pills $(7 \%)$, female sterilization (5\%), implants, male condom and IUCD (2\% each), and lactational amenorrhea methodLAM (I\%; KNBS and ICF Macro 20I0). Among sexually active unmarried women, however, the most commonly used method is male condom (I8\%) followed by injectables (I7\%), oral pills (6\%), female sterilization (2\%), IUCD and implants (I\% each; KNBS and ICF Macro 20I0). Public health facilities are the major source of modern methods of family planning for women (57\%), followed by private health facilities (36\%) while other sources such as mobile clinics, community-based distributors, shops, friends and relatives account for $6 \%$ (KNBS and ICF Macro 20I0). Among private providers, for- profit facilities and private pharmacies are the major sources of modern family planning methods (19\% and $10 \%$ respectively) while faith-based institutions account for 5\% (KNBS and ICF Macro 20I0). Estimates from the 2008-2009 KDHS further show that those who obtained a method from a public health facility were less likely to pay for the method compared to those who obtained a method from private providers. Payments in private health facilities could largely be for the services rendered (including consultation fee) given that family planning methods that are supplied by the government are supposed to be provided to clients free of charge.

With respect to pregnancy termination, estimates from the 2008-2009 KDHS show that among women aged 15-49 years who had ever had sex, I1\% had ever terminated a pregnancy (KNBS and ICF Macro 2010). The proportion of women who had ever had sex and had terminated a pregnancy was highest in Coast (17\%), followed by Western (14\%), Eastern and North Eastern (12\% each), Central (I 1\%), Nyanza (10\%), Rift Valley (9\%), and Nairobi $(6 \%)$ regions in that order (KNBS and ICF Macro 2010). In addition, the proportion of women who had ever terminated a pregnancy was highest among those aged $40-49$ years (19\%) and lowest among those aged below 20 years (3\%). It was also highest among those with no education (13\%) and lowest among those with secondary and above level of education (8\%; KNBS and ICF Macro 20I0). Available evidence indicates that abortion is one of the most common acute gynaecological ailments accounting for the longest hospital stay in comparison with other acute conditions in the country (Wamwana et al. 2006). In addition, a 2013 study that used patient-specific data for women who sought abortion-related care at health facilities estimated the rate of induced abortions in the country to be 48 per I, 000 women aged I5-49 years in 2012 (Republic of Kenya 2013). The study further found that those who sought abortion-related care comprised educated and uneducated, urban and rural as well as married, never married and divorced women (Republic of Kenya 2013). Slightly more than onethird (37\%) of the women had severe complications such as high fever, sepsis, shock and organ failure, which was an indication that abortion might have occurred under unsafe conditions (Republic of Kenya 20I3).

\section{Data and methods}

The study used a cross-sectional exploratory design involving observations of client-provider interactions 
during consultation and exit interviews with clients in 30 private health facilities in three counties in Kenya, namely, Kisumu (in Nyanza region), Nairobi, and Mombasa (in Coast region). The facilities were randomly sampled from among those that were members of the Reproductive Health Network $(\mathrm{RHN})$ or AMUA Franchise that is managed by Marie Stopes Kenya. Data collection took place between May and June 2013. Out of a total of $14 \mid$ observations that were conducted (62 in Kisumu, 58 in Nairobi and $2 \mathrm{I}$ in Mombasa), two observations were partially completed ( $I$ in Kisumu and $I$ in Mombasa) when it emerged during examination that the clients needed referrals to higher level facilities. The observations were conducted by trained nurses from outside the facilities to determine the nature and quality of services that clients received. The nurses used a structured checklist adapted from WHO Technical and Policy Guidance on Safe Abortion (WHO 2003) and the National Standards and Guidelines for Reducing Morbidity and Mortality from Unsafe Abortion in Kenya (Republic of Kenya 2012). They observed aspects of history taking, pre-procedure counselling, medical examination, provision of medical abortion, and post-abortion care counselling including family planning information and services.

Immediately after the observations, consenting clients were requested to participate in exit interviews to determine their perceptions of the information provided and their overall impression of the providers' behaviour during consultation. Interviews were completed with I 25 clients (48 in Kisumu, 56 in Nairobi and 2I in Mombasa). Another 6 interviews were partially completed while 8 clients who were observed during consultation refused the interviews. Information was collected on client background characteristics (such as age, education level, marital status, religious affiliation, and household assets and amenities), childbearing experiences and intentions, family planning knowledge and use, and perceptions about the services received. The interviews were conducted in English, Kiswahili or a mixture of both depending on the level of education of the clients by a team of research assistants who were paired with the nurses conducting the observations. Written informed consent was obtained from study participants before conducting the observations and exit interviews. Ethical and research clearance for the study was granted by the Institutional Review Boards of the Population Council and Marie Stopes International, the Ethics Review Committee of the Kenya Medical Research Institute (KEMRI), and the National Council for Science and Technology (NCST).

Analysis is restricted to 125 clients who were observed and successfully interviewed upon exit. It entails simple frequencies, cross-tabulations with Chi-square tests as well as estimation of multivariate logistic regression models. Simple frequencies are used to examine the socio-economic and demographic profiles of women seeking abortion services at private health facilities. The characteristics considered include study site, age, education level, marital status, religious affiliation, duration of residence, number of times the respondent has ever been pregnant, number of living children, and number of previous abortions. Cross-tabulations with Chisquare tests are used to examine variations in prior use of family planning by socio-economic and demographic characteristics of clients and to test whether differences, if any, are statistically significant. Multivariate logistic regression models are, on the other hand, estimated to examine whether there were significant differences in the likelihood of clients being counselled on family planning, being offered a method, or accepting a method by various background characteristics. The choice of logistic regression analysis was guided by the fact that the dependent variables are dichotomous outcomes. The characteristics considered include study site, age, education level, marital status, religious affiliation, duration of residence, household wealth index (based on reported assets and amenities), number of living children, number of previous abortions, and provider qualification. Table I presents the definition and measurement of variables included in the multivariate analysis. The standard errors of the estimates are adjusted for clustering of individuals within facilities and the results are presented as odds ratios with $95 \%$ confidence intervals. 
Table I: Definition and measurement of variables used in multivariate analysis

\begin{tabular}{|c|c|}
\hline Variable definition & Measurement \\
\hline \multicolumn{2}{|l|}{ Outcome variables } \\
\hline \multirow[t]{2}{*}{ Client counselled on family planning } & $0=\mathrm{No}$ \\
\hline & $\mathrm{I}=$ Yes \\
\hline \multirow[t]{2}{*}{ Client offered a family planning method } & $0=\mathrm{No}$ \\
\hline & $\mathrm{I}=$ Yes \\
\hline \multirow[t]{2}{*}{ Client accepted a family planning method } & $0=\mathrm{No}$ \\
\hline & $\mathrm{I}=$ Yes \\
\hline \multicolumn{2}{|l|}{ Covariates } \\
\hline \multirow[t]{2}{*}{ Study site } & $0=$ Mombasa $/$ Kisumu \\
\hline & $I=$ Nairobi \\
\hline Age & Single years (ranges from 16 to 43 ) \\
\hline \multirow[t]{2}{*}{ Education level } & $0=$ No schooling/pre-unit/primary \\
\hline & $\mathrm{I}=$ Secondary and above \\
\hline \multirow[t]{2}{*}{ Current marital status } & $0=$ Never $/$ formerly married \\
\hline & $\mathrm{I}=$ Married/living together \\
\hline Religious affiliation & $\begin{array}{l}0=\text { Protestant/other Christian/Muslim/Other } \\
\mathrm{I}=\text { Catholic }\end{array}$ \\
\hline Duration of residence & $\begin{array}{l}0=\text { Less than } 5 \text { years/visitor } \\
\mid=5 \text { years or more/always }\end{array}$ \\
\hline Household wealth status $^{a}$ & $\begin{array}{l}0=\text { Other sixty percent } \\
I=\text { Poorest forty percent }\end{array}$ \\
\hline Number of living children & Ranges from 0 to 6 \\
\hline Number of previous abortions & Ranges from 0 to 5 \\
\hline Provider qualification & $\begin{array}{l}0=\text { Clinical } / \text { medical officer } / \text { doctor } \\
\mathrm{I}=\text { Nurse } / \text { midwife }\end{array}$ \\
\hline
\end{tabular}

${ }^{\mathrm{a} B a s e d}$ on household assets and amenities.

\section{Results}

\section{Characteristics of clients}

Table 2 presents the distribution of respondents who were observed and interviewed upon exit by background characteristics and prior use of family planning. The distribution by background characteristics shows that the majority of respondents were aged between 20 and 29 years (66\%), had secondary and above level of education (64\%), were never married $(59 \%)$, and had lived at the place of residence for less than five years (49\%). In addition, more than half $(56 \%)$ had been pregnant more than once, $57 \%$ had no living children while $86 \%$ of those who had been pregnant more than once had had a previous abortion. 
Table 2: Percent distribution of clients who were observed and interviewed upon exit by background characteristics and ever use of family planning

\begin{tabular}{|c|c|c|c|}
\hline Characteristics & $\begin{array}{r}\text { Sample distribution } \\
(\%)\end{array}$ & $\begin{array}{l}\text { Ever used family } \\
\text { planning (\%) }\end{array}$ & $\begin{array}{r}\begin{array}{r}\text { Number of cli- } \\
\text { ents }\end{array} \\
\end{array}$ \\
\hline Study site & & $p=0.35$ & \\
\hline Nairobi & 44.8 & 82.1 & 56 \\
\hline Mombasa & 16.8 & 66.7 & 21 \\
\hline Kisumu & 38.4 & 77.1 & 48 \\
\hline Age group & & $\mathrm{p}<0.05$ & \\
\hline$<20$ years & 14.4 & 55.6 & 18 \\
\hline $20-29$ years & 65.6 & 78.1 & 82 \\
\hline 30 years and above & 20.0 & 92.0 & 25 \\
\hline Education level & & $p=0.05$ & \\
\hline Below secondary level & 36.0 & 66.7 & 45 \\
\hline Secondary level & 29.6 & 78.4 & 37 \\
\hline College/university level & 34.4 & 88.4 & 43 \\
\hline Marital status & & $p=0.29$ & \\
\hline Never married & 59.2 & 73.0 & 74 \\
\hline Married/living together & 27.2 & 82.4 & 34 \\
\hline Formerly married ${ }^{\mathrm{a}}$ & 13.6 & 88.2 & 17 \\
\hline Religious affiliation & & $p=0.12$ & \\
\hline Catholic & 29.6 & 73.0 & 37 \\
\hline Protestant/other Christian & 60.8 & 82.9 & 76 \\
\hline Muslim/other & 9.6 & 58.3 & 12 \\
\hline Duration of residence & & $p=0.78$ & \\
\hline$<5$ years/visitor & 48.8 & 75.4 & 61 \\
\hline 5 years or more & 32.8 & 78.1 & 41 \\
\hline Always & 18.4 & 82.6 & 23 \\
\hline Number of times pregnant & & $p<0.01$ & \\
\hline Once & 44.0 & 63.6 & 55 \\
\hline 2 or more times & 56.0 & 88.6 & 70 \\
\hline Number of living children & & $\mathrm{p}<0.05$ & \\
\hline 0 & 56.8 & 69.0 & 71 \\
\hline I & 19.2 & 87.5 & 24 \\
\hline 2 or more & 24.0 & 90.0 & 30 \\
\hline Number of previous abortions ${ }^{\mathrm{b}}$ & & $p=0.67$ & \\
\hline 0 & 14.3 & 90.0 & 10 \\
\hline I & 61.4 & 86.1 & 43 \\
\hline 2 or more & 24.3 & 94.2 & 17 \\
\hline All clients & 100.0 & 77.6 & 125 \\
\hline
\end{tabular}

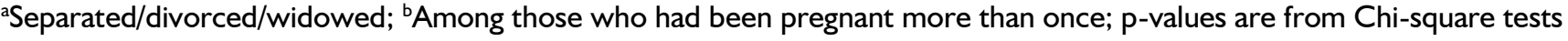
of differences in ever use of family planning by background characteristics.

\section{Prior use of family planning}

More than three-quarters (78\%) of the respondents had ever used a family planning method with no significant differences by study site, education level, marital status, religious affiliation, duration of residence, children ever born, and number of previous abortions (Table 2). There were, however, significant differences in the proportions of respondents that had ever used family planning by age, number of pregnancies and number of living children. In particular, the proportions of respondents that had ever used family planning was highest among those aged
30 years and above and lowest among those aged below 20 years $(p<0.05$; Table 2$)$. Similarly, the proportion of respondents that had ever used family planning was highest among those who had been pregnant two or more times and lowest among those who had been pregnant only once $(p<0.01)$. Ever use of contraception was also highest among those with two or more living children and lowest among those with no living child $(p<0.05)$.

Further analysis showed that the most common methods clients had ever used were male condoms $(44 \%)$, oral pills $(40 \%)$, injectables $(35 \%)$, and 
emergency pills (26\%; Figure I). In addition, $80 \%$ of the clients who had ever used family planning obtained a method themselves or together with their partners the last time while 19\% reported that their partners obtained the method. Among clients who obtained a method by themselves or together with their partners, $36 \%$ got it from private pharmacies, $35 \%$ from private health facilities, and $22 \%$ from public health facilities (not shown).

Figure 1: Percent distribution of clients who had ever used a family planning method by type of method

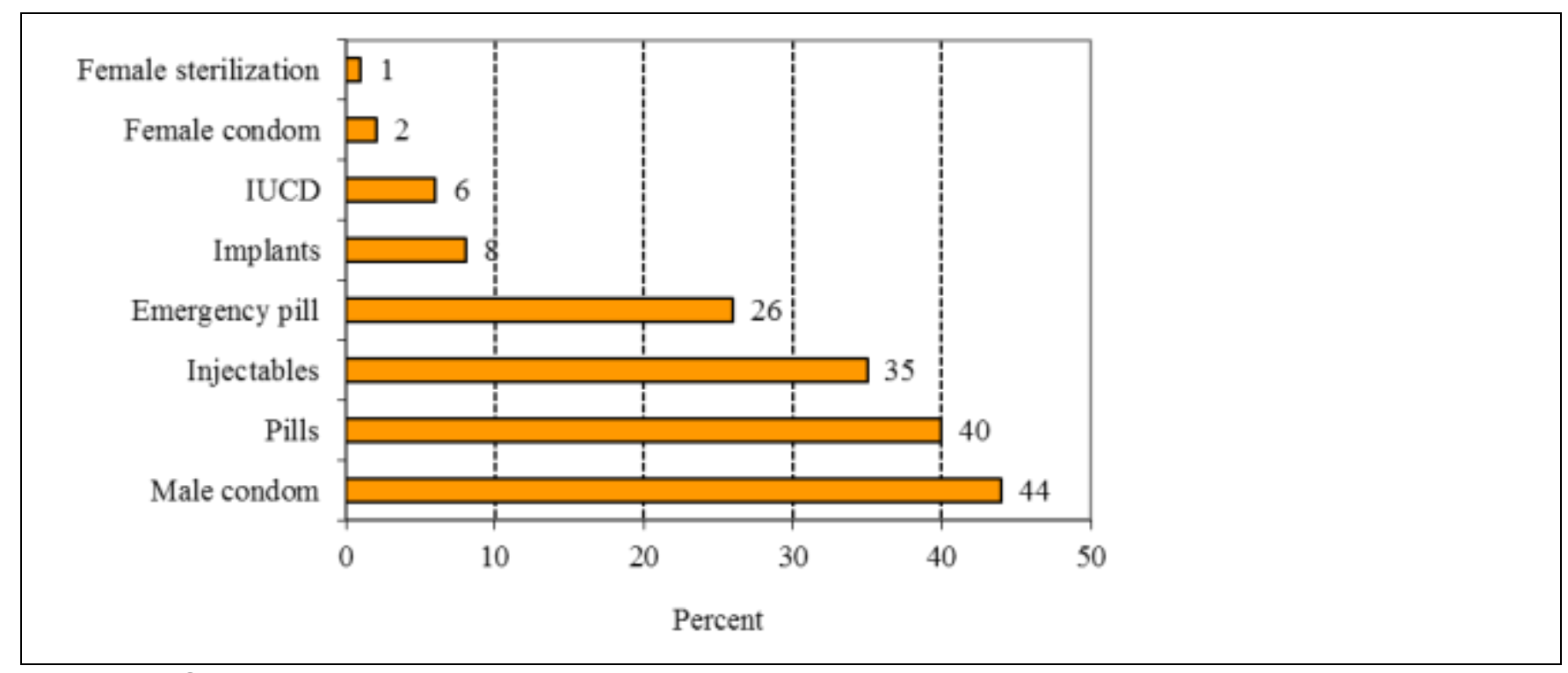

Notes: IUCD: Intra-uterine contraceptive device.

\section{Counselling on family planning}

Providers counselled clients on family planning in $80 \%$ of the consultations and offered clients a family planning method in less than half $(47 \%)$ of the consultations. Results from the multivariate logistic regression analysis show that clients in Nairobi were significantly less likely to be counselled on family planning compared to their counterparts in other sites $(p<0.01$; Table 3$)$. There were, however, no significant differences in the likelihood of clients being counselled on family planning by the other characteristics considered. The results further show that clients in Nairobi were significantly less likely to be offered a family planning method compared to those in Kisumu and Mombasa ( $<<0.01$; Table 3). There were also significant differences in the likelihood of clients being offered a family planning method by religious affiliation-the odds were more than three times higher among Catholic clients compared to those belonging to other religious denominations $(p<0.0$ I; Table 3). However, the likelihood of being offered a family planning method did not significantly differ by the other characteristics considered. 
Table 3: Odds ratios from multivariate logistic regression models predicting the likelihood of clients being counselled on family planning, being offered a method, and accepting a method

\begin{tabular}{|c|c|c|c|}
\hline Covariates & $\begin{array}{l}\text { Client counselled } \\
\text { on family planning }\end{array}$ & $\begin{array}{c}\text { Client offered a } \\
\text { method }\end{array}$ & $\begin{array}{c}\text { Client accepted a } \\
\text { method }\end{array}$ \\
\hline Study site $($ Nairobi $=I)$ & $\begin{array}{c}0.03^{* * *} \\
(0.01-0.22)\end{array}$ & $\begin{array}{c}0.1 I^{* *} \\
(0.02-0.58)\end{array}$ & $\begin{array}{c}1.92 \\
(0.39-9.52)\end{array}$ \\
\hline Age (single years) & $\begin{array}{c}0.97 \\
(0.90-1.04)\end{array}$ & $\begin{array}{c}1.02 \\
(0.95-1.09)\end{array}$ & $\begin{array}{c}0.99 \\
(0.91-1.08)\end{array}$ \\
\hline Education level (secondary and above $=\mathrm{I}$ ) & $\begin{array}{c}0.79 \\
(0.15-4.23)\end{array}$ & $\begin{array}{c}0.99 \\
(0.42-2.38)\end{array}$ & $\begin{array}{c}1.85 \\
(0.86-3.98)\end{array}$ \\
\hline Marital status (married/living together $=\mathrm{I}$ ) & $\begin{array}{c}6.18 \\
(0.61-62.43)\end{array}$ & $\begin{array}{c}2.02 \\
(0.52-7.82)\end{array}$ & $\begin{array}{c}1.99 \\
(0.78-5.10)\end{array}$ \\
\hline Religious affiliation (Catholic $=I$ ) & $\begin{array}{c}3.09 \\
(0.76-12.56)\end{array}$ & $\begin{array}{c}3.45 * * \\
(1.36-8.72)\end{array}$ & $\begin{array}{c}1.40 \\
(0.58-3.42)\end{array}$ \\
\hline $\begin{array}{l}\text { Duration of residence }(5 \text { years or } \\
\text { more }=I)\end{array}$ & $\begin{array}{c}0.88 \\
(0.46-1.69)\end{array}$ & $\begin{array}{c}1.42 \\
(0.54-3.78)\end{array}$ & $\begin{array}{c}0.90 \\
(0.42-1.94)\end{array}$ \\
\hline $\begin{array}{l}\text { Household wealth status (poorest forty } \\
\text { percent }=I \text { ) }\end{array}$ & $\begin{array}{c}0.4 I \\
(0.10-\mid .7 I)\end{array}$ & $\begin{array}{c}1.20 \\
(0.35-4.19)\end{array}$ & $\begin{array}{c}2.36 \\
(0.78-7.16)\end{array}$ \\
\hline Number of living children & $\begin{array}{c}1.13 \\
(0.65-1.95)\end{array}$ & $\begin{array}{c}0.97 \\
(0.70-1.34)\end{array}$ & $\begin{array}{c}1.09 \\
(0.79-1.50)\end{array}$ \\
\hline Number of previous abortions & $\begin{array}{c}2.35 \\
(0.98-5.64)\end{array}$ & $\begin{array}{c}1.22 \\
(0.56-2.62)\end{array}$ & $\begin{array}{c}0.90 \\
(0.47-1.73)\end{array}$ \\
\hline Provider qualification (nurse/midwife $=I$ ) & $\begin{array}{c}0.53 \\
(0.14-2.06)\end{array}$ & $\begin{array}{c}0.50 \\
(0.14-1.74)\end{array}$ & $\begin{array}{c}1.23 \\
(0.4 \mid-3.65)\end{array}$ \\
\hline Number of cases & 117 & 117 & 117 \\
\hline Wald Chi-square statistic & 45.71 & 27.11 & 17.36 \\
\hline$p$-value & 0.00 & 0.00 & 0.07 \\
\hline
\end{tabular}

$95 \%$ confidence intervals are in parentheses; ${ }^{*} p<0.05 ;{ }^{* *} p<0.01$.

\section{Client acceptance of a method}

More than one-third (36\%) of the clients who were observed and successfully interviewed upon exit accepted a family planning method. Results from the multivariate logistic regression analysis show that there were no significant differences in the likelihood of clients accepting a method by the background characteristics considered (Table 3). Further analysis showed that clients mostly accepted injectables $(40 \%)$, male condom (33\%), pills $(20 \%)$, implants (18\%), and intra-uterine contraceptive device-IUCD (I8\%). In addition, II\% of the clients who accepted a method had not previously used family planning while among those who had previously used a method, $60 \%$ chose a different method. Figure 2 presents the distribution of clients who accepted a different family planning method from what they had previously used by type of method ever used and method accepted during the visit. The results show that the shift was marked by dramatic declines in the uptake of oral and emergency pills and increases in the acceptance of injectables, IUCD and implants. 
Figure 2: Distribution of clients who accepted a different family planning method from that previously used by type of method ever used and method accepted during the visit

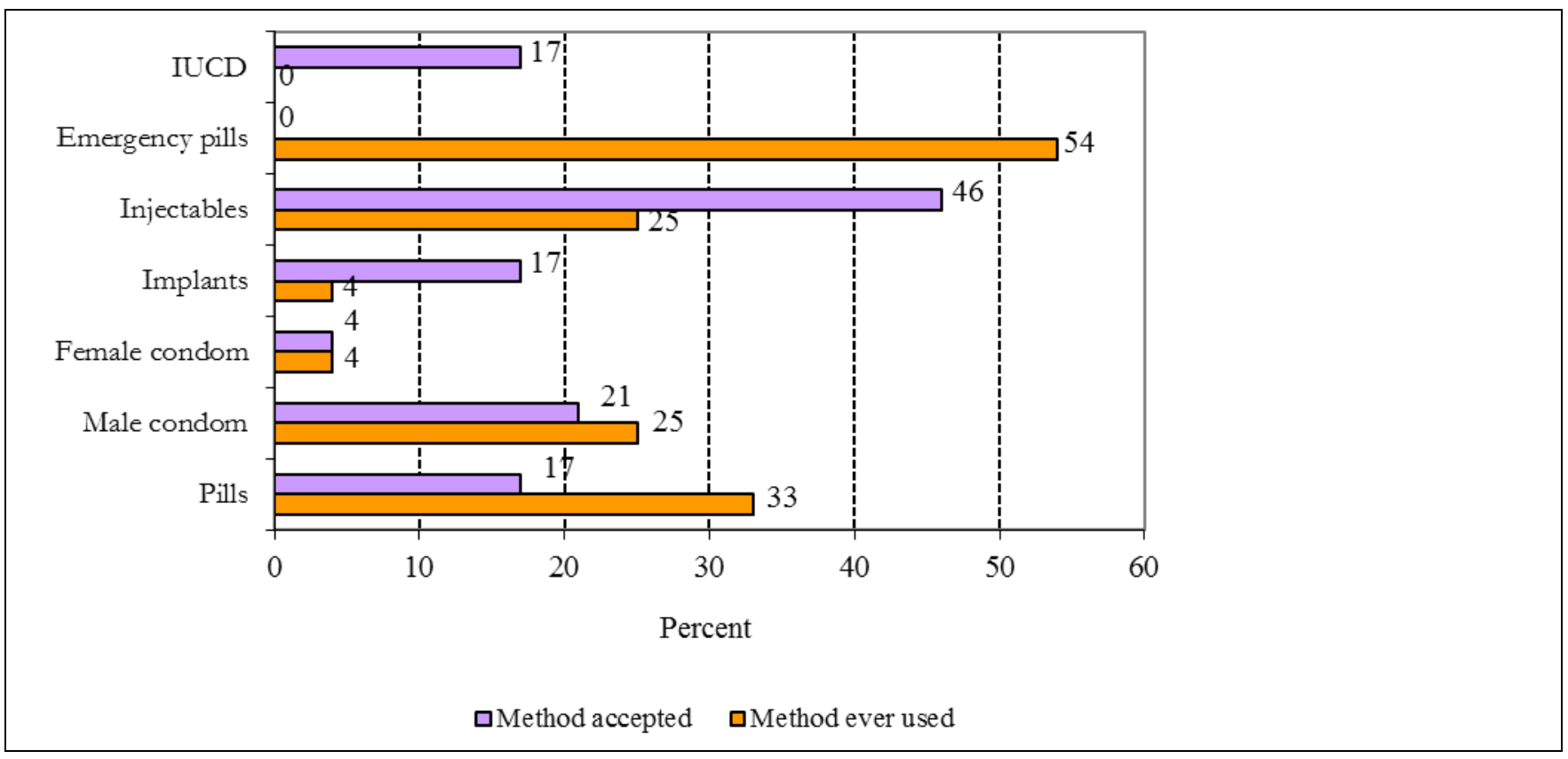

Notes: IUCD: Intra-uterine contraceptive device.

\section{Discussion and conclusion}

One major finding of this paper is that most clients seeking abortion services at private health facilities that participated in the study were young, educated and unmarried women. In addition, among those who had been pregnant more than once, the proportion that had a previous abortion was very high. The implication is that clients seeking abortion services at private health facilities are constantly exposed to irregular unprotected sex. Although the majority of clients had used a family planning method before, it was mostly short-acting methods such as condoms, injectables, oral and emergency pills. Moreover, repeat abortions could be due to inconsistent use of the methods although the study did not ask about frequency of prior use. These findings suggest the need to promote either consistent use of short-acting family planning methods or the use of long-term methods among clients seeking abortion services at private health facilities in the country. Long-term methods, in particular, have several advantages. Besides the possibility of long-term use, the methods are not dependent on compliance and correct use by clients, their efficacy begins almost immediately after insertion, and they have low rate of complications and side-effects (Bahamondes 2008; Blumenthal et al. 20II). The need for longterm methods was also evident from the finding that among clients who had ever used family planning and accepted a method during the visit, the majority chose a different method with the shift being charac- terized by dramatic declines in the uptake of shortacting methods (oral and emergency pills) and increases in the acceptance of long-term methods (injectables, IUCD and implants).

The findings of the paper further show that providers did not counsel clients on family planning in about one-fifth of the consultations while clients were offered a method in less than half of the consultations. WHO recommends that all women seeking abortion or post-abortion care services should be provided with family planning information, counselling and methods and that most methods can be initiated immediately following surgical or medical abortion procedures (WHO 2012). Moreover, the National Standards and Guidelines in Kenya recognize family planning as critical for reducing unwanted pregnancies, unsafe abortion and related morbidity and mortality (Republic of Kenya 2012). The Guidelines further stipulate that all women, men and young people should be offered family planning information and services provided that they meet medical eligibility criteria (Republic of Kenya 2012). The fact that a fraction of the women seeking abortion services at private health facilities were not counselled on family planning and more than half were not offered a method indicates that the provision of these services does not meet WHO or national standards and guidelines. Although the study did not determine the reasons for non-provision of family planning information and methods, these findings suggest the need to widely disseminate existing 
international and national service standards and guidelines among private providers offering abortion services in the country.

Another finding that is worth noting is the significantly lower likelihood of counselling clients on family planning or offering clients a method among private providers in Nairobi compared to those in Mombasa and Kisumu counties. First, being the region with the second highest CPR in the country, one would expect a greater likelihood of providers in Nairobi to counsel or offer clients family planning methods compared to their counterparts in Mombasa or Kisumu counties which have lower CPR. Second, Nairobi has historically been one of the mostfavoured regions for rural to urban migration because, being the capital city and major urban centre, it is highly developed and has more opportunities, better infrastructure and services (Otiso 2005). One would therefore expect better quality services in the region compared to other counties. The study did not, however, collect information that would allow for determining why the likelihood of counselling clients on family planning or offering them a method was significantly lower in Nairobi compared to other sites. Nonetheless, available evidence indicates that the quality of care in private health facilities might vary due to the inability of government regulatory bodies to adequately monitor and enforce standards in the sector (Mills et al. 2002; Zwi et al. 200I).

The findings of this paper might, however, be influenced by the limitations of the study. For instance, it is likely that observing providers during consultation may bias their behaviour in a positive way. To address this issue, observers were people with medical qualifications. It was expected that this would likely raise the comfort levels of the providers such that their behaviours become normative. In addition, it was emphasized during training and at the beginning of the observation tool that the observers should let the providers know that they (observers) were not there to evaluate them (providers) and that the observers were not experts who could be consulted during the session. The second limitation of the study arises from the fact that although facilities were randomly sampled from among those that were members of RHN or AMUA Franchise, the clients were not. Rather, clients were observed or interviewed upon exit based on their willingness to participate in the study. Providers first explained to the clients about the study and if they were willing to participate, the nurses and the exit interviewers were called. It could be that those who accepted to participate in the study were a select group of abor- tion clients; their experiences may not therefore be representative of all clients seeking abortion services from private health facilities or from elsewhere including public health facilities and unskilled providers.

In spite of the limitations, the findings of this paper show that the provision of family planning services to clients seeking abortion services in private health facilities in Kenya does not meet the existing international and national standards and guidelines. There is therefore need for strategies to improve the provision of the services in the sector. Specific strategies will, however, vary depending on the reasons for non-provision of the services at the facilities. Nonetheless, the strategies might include updating the skills of private providers on family planning service provision especially the provision of long-acting and permanent methods, wide dissemination of existing international and national service standards and guidelines among private providers, mechanisms for monitoring and enforcing standards in the sector by the government regulatory bodies such as through franchises, as well as implementing medical reminders for private providers to offer family planning services to abortion clients.

\section{Acknowledgement}

The study that provided the data for this paper was funded by UKaid from the Department for International Development (DFID) through STEP UP (Strengthening Evidence for Programming on Unintended Pregnancy) Research Programme Consortium. The study was implemented by the Population Council in collaboration with Marie Stopes Kenya (MSK) and the Reproductive Health Network (RHN). Ethical and research clearance for the study was granted by the Institutional Review Boards of the Population Council and Marie Stopes International, the Ethics Review Committee of the Kenya Medical Research Institute (KEMRI), and the National Council for Science and Technology (NCST). The views expressed in the paper are, however, those of the authors and do not necessarily reflect the views of the funding or implementing agencies.

\section{Authors' Contributions}

FO conducted the analysis, interpretation of results, and drafting of the manuscript. WL and HB were involved in the conceptual design of the study and in reviewing the manuscript for substantial intellectual content. 


\section{References}

Bahamondes, L. 2008. Interventions Subdermal implantable contraceptives versus other forms of reversible contraceptives or other implants as effective methods of preventing pregnancy: Reproductive Health Library commentary. Geneva: World Health Organization.

Benson, J. 2005. "Evaluating abortion-care programs: old challenges, new directions." Studies in Family Planning 36(3): 189-202.

Berman, P. and Rose, L. 1996. "The role of the private providers in maternal and child health and family planning services in developing countries." Health Policy and Planning II (2): I 42-I 55.

Blumenthal, P.D., Voedisch, A. and GemzellDanielsson, K. 20II. "Strategies to prevent unintended pregnancy: increasing use of long acting reversible contraception." Human Reproduction Update 17(I):121-137.

Brookman-Amissah, E. and Moyo, J.B. 2004. "Abortion law reform in sub-Saharan Africa: no turning back." Reproductive Health Matters 12(24 Suppl):227-34.

Bruce J. 1990. "Fundamental elements of the quality of care: a simple framework." Studies in Family Planning 2I(2):6I-9I.

Brugha, R. and Zwi, A. 1998. "Improving the quality of private sector delivery of public health services: challenges and strategies." Health Policy and Planning 13(2): 107-120.

Bustreo, F., Harding, A., and Axelsson, H. 2003. "Can developing countries achieve adequate improvements in child health outcomes without engaging the private sector?" Bulletin of the World Health Organization 8I(12):886-895.

Centre for Reproductive Rights. 2010. The impact of Kenya's Restrictive Abortion Law. New York: Centre for Reproductive Rights. Accessed at: publications@reprorights.org.

Gresh, A. and Maharaj, P. 20I4. "Termination of pregnancy: perspectives of female students in Durban, South Africa." African Population Studies 28(I):68I-690.

Hutchinson, P.L., Do, M. and Agha, S. 20II. "Measuring client satisfaction and the quality of family planning services: a comparative analysis of public and private health facilities in Tanzania, Kenya and Ghana." BMC Health Services Research II (203): I-I 7.

Kenya National Bureau of Statistics (KNBS) and ICF Macro. 20I0. Kenya Demographic and Health Sur- vey 2008-09. Calverton, Maryland: KNBS and ICF Macro.

Mills, A., Brugha, R., Hanson, K. and McPake, B. 2002. "What can be done about the private health sector in low-income countries?" Bulletin of the World Health Organization 80(4):325-330.

Ministry of Health [Kenya]. 2003. Kenya National Post Abortion Care Curriculum: Trainer's Manual. Nairobi: Ministry of Health.

Ong'ech, J., Osur, J., Makanyengo, M., Mathai, M., Gebreselassie, H. and Brookman-Amissah, E. 2008. The status of Misoprostol use in Kenya. Nairobi: Ipas Africa Alliance and the National Health and Development Organization (NAHEDO).

Otiso, K.M. 2005. "Kenya's secondary cities growth strategy at crossroads: which way forward?" Geo Journal 62(I-2): II 7-I28.

Patouillard, E., Goodman, C.A., Hanson, K.G., and Mills, A.J. 2007. "Can working with the private for-profit sector improve utilization of quality health services by the poor? A systematic review of the literature." International Journal for Equity in Health 6(I7): I-II.

Republic of Kenya. 20I0. Constitution of Kenya 2010. Nairobi: Republic of Kenya.

Republic of Kenya. 2012. Standards and Guidelines for Reducing Morbidity and Mortality from Unsafe Abortion in Kenya. Nairobi: Republic of Kenya/Ministry of Medical Services.

Republic of Kenya. 20I3. Incidence and complications of unsafe abortion in Kenya: Key findings of a national study. Nairobi: African Population and Health Research Centre, Ministry of Health (Kenya), Ipas, and Guttmacher Institute.

Sedgh, G., Henshaw, S., Singh, S., Åhman, E. and Shah, I.H. 2007. "Induced abortion: estimated rates and trends worldwide." Lancet 370(9595): 1338-45.

Shah, I. and Åhman, E. 2010. "Unsafe abortion in 2008: global and regional levels and trends." Reproductive Health Matters 18(36): 90- I0I.

United Nations. 2010. Millennium Development Goal Report 2010; Trends in Maternal Mortality: 19992008. New York: United Nations.

Wamugi, S., Yegon, E., Fetters, T., Wanaswa, L., and Msipa-Ndebele, S. 20I4. “Women's perceptions about abortion in their communities: perspectives from Western Kenya." Reproductive Health Matters 22(43): I49-I 58.

Wamwana, E.B., Ndavi, P.M., Gichangi, P.B., Karanja, J.G., Muia, E.G. and Jaldesa, G.W. 2006. "Socio-demographic characteristics of patients ad- 
mitted with gynaecological emergency conditions at the provincial general hospital, Kakamega, Kenya." East African Medical Journal 83(I2):659665.

World Health Organization (WHO). 2004. Unsafe abortion: global and regional estimates of incidence of unsafe abortion and associated mortality in 2000. Geneva: World Health Organization.

World Health Organization (WHO). 20II. Unsafe abortion: global and regional estimates of incidence of unsafe abortion and associated mortality in 2008, $6^{\text {th }}$ edition. Geneva: World Health Organization.

World Health Organization (WHO). 20I2. Safe abortion: technical and policy guidance for health systems, $2^{\text {nd }}$ edition. Geneva: World Health Organization.

Zwi, A.B., Brugha, R. and Smith, E. 200I. "Private health care in developing countries: if it is to work, it must start from what users need." $B M J$ 323(73II):463-464. 